\title{
A Tentative Approach of Translation Education under the Constructivism Theory
}

\author{
Juan Li \\ Department of College English, Zaozhuang University, Zaozhuang, 277100, China
}

Keywords: Constructivism Theory. Translation. Teaching program

\begin{abstract}
Constructivism theory always concentrates on students' dominant position and significance of cooperative learning development in knowledge construction. It takes the biggest objective of teaching as offering help in cognitive construction completion of students. By conducting constructivism theory to translation teaching program, a better effect of students' translation ability improvement could be got. In this article, constructivism theory would be analyzed, situation of translation teaching in colleges and universities would be elaborated, and translation teaching methods under constructivism theory shall be provided.
\end{abstract}

\section{Introduction}

Instead of making students acquire English language structure, enrich linguistic knowledge of English, and enhance the educational level, the objectives of translation teaching program in colleges and universities are designed to systematically disseminate rules, theories, methods and techniques of translation, and with analysis of thinking process and psychological activities as the teaching content.

\section{Analysis of constructivism theory}

Constructivism theory is one of important branches of cognitive psychology with respective persons like Piaget, Sternberg and Vygotsky etc. Theory claims that:

1). Effectively with students as centre, emphasizing the students' active exploration of knowledge and initiatively discovering the contribution of their knowledge to constructivism theory. Students are learning subjects, they shall construct new knowledge and experience through serious practice in the existing knowledge system, instead passively accept knowledge.

2). Study is a mental representation process for constructivism theory students. Instead of migration the knowledge from outside into memories, students would apply the interaction with external world to new understanding of constructivism theory, which is on the basis of existing experience.

3). Students are subject of learning, cognition and information process, and they are also active constructor of the sense of knowledge. The amount of knowledge they have is always depending on the relevant knowledge gained from students' own experience, where teachers always act as supporters and helpers. Teachers shall take students as the real centre to motivate them with their autonomy given off.

4). Knowledge is not an objective characterization; it is a kind of understanding of the world built by interaction between students and situation. A real language environment is important for language learning, study is always connected with some social cultural background or namely scenario. Study is a process for students to apply active exploration and coordination to colorful scenarios. Knowledge is constructed with behavior patterns and study is a main process to create such patterns, with teaching as a supporter to provide relevant knowledge for this construction. Constructivism theory completely takes students as centers, with relevant questions as media, students could systematically review and sum up with teachers' effective help, to implement mastery achievement through a comprehensive study between existing and new knowledge. Therefore, a knowledge system would be constructed. 


\section{The situation of translation teaching in colleges and universities}

Translation is an exchange process between two different languages. This is a process of thought transformation and a cross-cultural social work that translators do their best to deliver information precisely from one language to another. Translation teaching class in not totally the same to develop language teaching, that is to say not simply decode linguistic information, translation teaching also reconstructs the meaning on the basis of decoding, so that students could be facilitated to complete the transformation process from language learning to language application. As a analysis procedure of thinking process and mental activity, English translation teaching program place students into translation activities with a deep understanding of migrating contents from one language to another. Therefore, translation teaching courses in our colleges and universities shall put attention of skill explanation away, overlook practice lectures, and do not waste a large amount of time on traditional teaching methods of passing on words and grammars. By observing students' actual situation and target of professional training, these courses shall apply translation theories to translation work practice as guidance and focus on students' translation ability training and developing. One of the most important reasons for unsatisfied results produced by English translation teaching program in our colleges and universities is traditional teaching method has been adopted - fish given, which makes limited space for quality and effect improvement. Translation teaching program laid particular emphasis on final product of translation in conventional sense, so called translated text, however, by this way, the thinking ability development of students' translation activities might be neglect. Hence, students shall enhance related translation knowledge continuously lectured under teachers' hand guiding. The main procedure is: a). Translation techniques and theories are lectured by teachers; b). Related translation tutorials shall be assigned later; c). Students' translation ability and techniques would be improved gradually through translation practice process; d). Evaluation criterion and final translation text shall be elaborated via one by one correction and explanation by teachers.

And deficiencies of the traditional teaching program are that as following: a). Translation knowledge is lectured directly to students; the learning enthusiasm and learning motivation of students could not be simulated by unilateral cramming knowledge into their head; b). Overwhelming emphasis on the role of teachers and neglect role of students make students initiative can not be acted; at the same time, consciousness of innovation could not be activated; c). Overly focused on amplification and omission in micro translation methods, and omit the control of translation procedure, so students would be blank on when and how to use translation techniques learned after into translation practice.

\section{Translation Teaching Method under Constructivism Theory}

\section{Situational Method}

There is an interaction between students and external environment which is important for knowledge meanings. One of the vital tasks is to create a real or close to the real subject-related learning situation in accordance with contents and objectives of translation courses. Thus, teaching materials used shall stick to current social reality. Beside literature, real materials and examples involving diplomatic documents, business trade and scientific technology shall be added in. During the teaching program, a reasonable increase of case study shall be considered like: business translation, business letters translation, documents translation and translation for global communication etc. Teacher could also implement situation method by videos and online resources, such as English movies, English news, popular science and personage's biography etc. to provide real or simulative English learning situation. Certainly, object teaching would be applied to motivate students to participate in interacting study with maximum limit, and accomplish the translation knowledge application and construction of translation significance in the learning process.

\section{Group Work}

Construction of individual can only implement a second meaning construction on higher level after being verified by others' meaning construction. With social communication in learning process, 
the support of homogeneity could be reflected by promotion of students' subjectivity development and socialize. It emphasizes on taking teaching process as a major carrier to realize humane interaction to reach the teaching goal. Daily communication understanding shall be in line with translation process in principle. Actually, the group work is an initiative learning process that based on respective cognitive structure among students. Each of the students shall seriously think about how to complete learning tasks, and everyone's thought achievement shall be shared with group members to improve their self-study ability and learning effectiveness.

\section{Bridge-building}

Translation knowledge is not merely gained from teachers; it is absorbed by proactive meaning construction with others' help under relevant social background. Teachers shall position the relationship with students correctly to switch the old teaching mode-teacher centered to the new learner centered mode. Teachers are no longer the authority in teaching procedure; on the contrary, the actual demand, interests and strength and weakness of students shall be considered, and then teachers and students could study together. Experience in previous teaching program, teachers are responsible for translation materials selection, emphases and difficulties explanation and providing reference answers. Students always accept assignments and reference answers passively. However, teaching practice shows that this could not comply with actual situation and ignore students' interests and personality, lack of trust in students' ability and consciousness, and somehow limit students' subjective initiative. New teaching method advocates waive the pattern of teacher centered to have full impact of students' subjectivity and teachers guidance and help, in which way the keen interests of students; what's more, with the help of setting situation as required and referential cues between new and old knowledge, students could construct the knowledge meaning they have learnt to form the solutions to relevant issues, and then the interaction between teachers and students could be realized. Translation theory is essential as criteria and basis of evaluation. In translation classes, students shall experience mature idea and principle of translation at first stage, later on study specific translation methods and techniques, and then implement harmonious development. Teachers shall explain translation theory in the beginning of translation teaching program to let students have preliminary understanding of translation criteria and principles, and toward this end in view, make large number of practice to realize the requirements of translation as similar in appearance and spirit.

\section{Task Designs}

After setting good study situation, teachers of translation courses shall design reasonable learning tasks according to students' study objectives. Sukhomlinskii, a famous educationalist of Soviet Union, said the true meaning of education is to show students how to study. In traditional teaching method, teachers would like to force-feeding knowledge to students with ignorance of stimulating and developing the ability of solving actual problems. Only with reasonable learning tasks, could students be encouraged to implement learning autonomy by multi-media, internet resources and group work, proactive construction and assessment of autonomy supervision could be done for social knowledge. Only in this way, are the students able to be said that they have true productive learning and are subject of individual creative study and practice developer. As language training process, the translation learning program shall pay high attention on a good deal of language input, especially those true, interesting and practical translation materials that can develop real and meaningful Chinese - English bilingual translation activities, so that bilingual input for different subjects and different genres. At the same time, the cultivation of students' language information input method shall be highlight in overall language environment other than limited in traditional translation theory class. Students are encouraged to participate in English corner internal and external school life and social practice, to enhance their own language sense, enrich means of expression of Chinese and English.

\section{Online Teaching Method}

Advanced teaching method and language input are desired in modern translation teaching program. As extensive application of computer network technology (CNT), great development opportunity has been brought into translation teaching program in colleges and universities. Teachers could made or surf the internet to get useful computer courseware and select meaningful bilingual translation 
contents to guide students to study with computer and implementation with program procedure requirements. The application of internet is also able to provide real-time update for teaching resources. For example, I have actively encouraged students to search latest translation information for study in or after classes during my teaching program or find suitable translation resources to train themselves through internet, and the translation learning effectiveness of students could be improved greatly.

\section{(F) Introspection Teaching Method}

The view of constructivism theory is an understanding in-depth of events under self experience of each person. Therefore, students have different views of events all the time, and there is no such only right answer to these events. That is to say, the answer to translation is not uniqueness, and this is not full negative of teachers' guidance. Based on guiding students' active knowledge construction activities, teachers have to lead correctly in understanding of what they taught. This because the understandings of students may have uncertainly changes and teachers shall guide in time: assent what have to be assented and correct what have to be corrected. Identified significance control of translation knowledge learnt by students could be accomplished.

\section{Conclusion}

To sum up, the translation teaching program under constructivism theory is in line with characteristics of college students and training objectives of translation teaching program in colleges and universities. With the guide of the theory, the interaction and cooperation of teachers and students could tackle critical points together in the teaching program. When facing the real problem in translation, students have the ability to construct new knowledge on the basis of their own experience to get into working status faster, and then the English translation ability could be improved.

\section{References}

[1] Wu Xiaojun: “Interaction” Construction of English Translation Teaching Mode, Foreign Language Research, 2007 (4).

[2] Lai Defu: Higher Vocational Business English Translation Teaching Program, Journal of Fujian Institute of Education, 2009 (4).

[3] Zhang Jianzhuang: Taking Employment As The Orientation, Cultivation of Students' Ability of Translation Practice Shall Be Focused, Business Culture, 2009 (7).

[4] Wang Yuxi: Discussion on Several Issues of College English Teaching Program, Chinese Translators Journal, 2010 (7). 